\title{
Partially bio-based thermoplastic elastomers by physical blending of poly(hydroxyalkanoate)s and poly(ethylene-co-vinyl acetate)
}

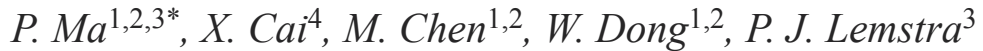 \\ ${ }^{1}$ The Key Laboratory of Food Colloids and Biotechnology of Ministry of Education, 1800 Lihu Road, 214122 Wuxi, \\ China. \\ ${ }^{2}$ School of Chemical and Material Engineering, Jiangnan University, 1800 Lihu Road, 214122 Wuxi, China. \\ ${ }^{3}$ Department of Chemical Engineering and Chemistry, Eindhoven University of Technology, 5612 Eindhoven AZ, the \\ Netherlands. \\ ${ }^{4}$ School of Food Science and Technology, Jiangnan University, 1800 Lihu Road, 214122 Wuxi, China
}

Received 16 January 2014; accepted in revised form 19 March 2014

\begin{abstract}
Partially bio-based thermoplastic elastomers (bio-TPE) were designed and prepared by physical blending a commercial grade poly(hydroxyalkanoate)s (PHBM, Metabolix) and poly(ethylene-co-vinyl acetate) (EVA). The PHBM is miscible with EVA90 which has a vinyl acetate (VA) content of $90 \mathrm{wt} \%$ while it is not miscible with EVA at low VA content ( $\leq 70 \mathrm{wt} \%$ ). The PHBM/EVA90 blends exhibit high tensile strength and typical thermoplastic elastomeric characteristics e.g. high elongation at break (>800\%), good strain-recovery $(>60 \%)$ and melt processability. The spherulite growth rate of PHBM decreases with increasing EVA90 content. Consequently, a large number of fine PHBM spherulites were formed in the blends. The spherulites act as physical crosslink-points leading to a thermoreversable network in the blends. Such network and elastic EVA90 molecules result in the thermoplastic and elastomeric characteristics of the PHBM/EVA90 blends.
\end{abstract}

Keywords: polymer blends and alloys, poly(hydroxybutyrate), poly(ethylene-co-vinyl acetate), miscibility, thermoplastic elastomer

\section{Introduction}

Polymers that derived from biomass have received considerable attention due to the sustainability issue and environment concern. Poly(hydroxyalkanoates) (PHAs) are synthesized and accumulated intracellularly by a number of micro-organisms $[1,2]$. The best-known PHA is poly(3-hydroxybutyrate) (PHB) discovered in Bacillus megaterium by Lemoigne in 1926 [3]. PHB is a semi-crystalline thermoplastic with niche applications due to its biocompostability under both aerobic and anaerobic conditions, biocompatibility and renewable nature [4]. The mechanical and thermal properties of PHB are similar to those of poly(propylene). However, poly(propylene) cannot be substituted by PHB yet since there are many drawbacks which limit the applications of PHB, e.g. high production cost, poor processability and brittleness.

The brittleness of PHB is ascribed to large spherulites and cracks inside of the spherulites [5]. Consequently, PHB has low elongation at break $\left(\varepsilon_{\mathrm{b}} \sim 3 \%\right)$ and low impact toughness $\left(\sigma_{\mathrm{i}} \sim 2 \mathrm{~kJ} / \mathrm{m}^{2}\right)[6]$. Techniques such as synthesis of PHB copolymers by biological modification [7-9], blending [6, 10-14] and improvement on processing conditions $[15,16]$ have been developed to minimize the drawbacks.

\footnotetext{
*Corresponding author, e-mail: pimingma@hotmail.com (C) BME-PT
} 
Synthesis of PHB copolymers could improve the toughness but compromise the strength and crystallization rate. On the other hand, blending is preferably used to toughen PHB.

The toughness of PHB could be improved by incorporation of rubbers. The $\sigma_{\mathrm{i}}$ was increased by $440 \%$ after addition of epoxy natural rubber using maleatedpoly(butadiene) as a compatibilizer [10]. The $\varepsilon_{\mathrm{b}}$ of PHB was increased to $10 \%$ after addition of $20 \mathrm{wt} \%$ poly(hydroxyoctanoate) accompanied by a considerable reduction in tensile strength, crystallization temperatures $\left(T_{\mathrm{c}}\right)$ and melting temperatures $\left(T_{\mathrm{m}}\right)$ [11]. The $\varepsilon_{\mathrm{b}}$ of PHB was even increased by a factor of 50 after addition of cellulose nanowhiskers using poly(ethylene glycol) as a plasticizer [12]. In another study, the ductility of poly(3-hydroxybutyrate-co-3hydroxyvalerate) $(\mathrm{PHBV}, \mathrm{HV}$ content $=12 \mathrm{~mol} \%)$ was considerably enhanced by incorporation of $20 \mathrm{wt} \%$ bisphenol-A (BPA) ascribing to a formation of hydrogen bond network between the two components [13]. The yield stress and $\varepsilon b$ of the PHBV/BPA $(80 / 20, \mathrm{wt} / \mathrm{wt})$ blend were reported to be $16 \mathrm{MPa}$ and $370 \%$ respectively. In our previous study, both $\varepsilon_{\mathrm{b}}$ and $\sigma_{\mathrm{i}}$ of PHB were increased by melt blending with biodegradable copolymers, i.e. poly(d,l-lactic acid) and poly(butylene succinate). The $\varepsilon_{\mathrm{b}}$ and $\sigma_{\mathrm{i}}$ were further improved via in situ compatibilization using peroxide as a free radical initiator $[6,14]$.

Blending is an effective and economic route to improve mechanical properties of polymers, however the toughness of PHB was only increased to a certain extent by blending with immiscible (co-)polymers. Some miscible (co-)polymers were blended with PHB in literatures such as poly(methyl methacrylate) [17], poly(ethylene oxide) [18] and poly (vinyl acetate) [19]. However, the effect of the miscible (co-)polymers on the mechanical properties of PHB was rarely studied. PHB-based thermoplastic elastomer (TPE) was even less reported.

The prime objective of this paper is to provide a method to prepare partially bio-based thermoplastic elastomers by physical blending PHBM and poly(ethylene-co-vinyl acetate) (EVA) copolymer. In the first part, the effect of vinyl acetate (VA) content on the miscibility, morphology and mechanical properties of the PHBM/EVA blends were investigated. In the second part, mechanical properties and morphology of the miscible PHBM/EVA blends were studied in detail and a mechanism for the thermoplastic elasticity was proposed based on the relation between properties and morphology. The thermoplastic elastomeric behavior of PHBM via melt blending with EVA, to the best of the authors' knowledge, has not been reported yet, which might broaden the application range of this polymer.

\section{Experimental details \\ 2.1. Materials}

Commercial grade poly(hydroxyalkanoate)s (Mirel ${ }^{\mathrm{TM}}$ M6000) was supplied by Metabolix, Inc. USA, which is a mixture of poly(3-hydroxybutyrate) and poly (3-hydroxybutyrate-co-4-hydroxybutyrate). Since the two components are miscible, the mixture shows single phase morphology and thus is referred to as PHBM in this paper. EVA copolymers (Levapren ${ }^{\circledR}$ EVM) with VA contents from 40 to $90 \mathrm{wt} \%$ were supplied by Lanxess Chemical Co., Ltd.. The EVA with VA content of $\mathrm{x} w \mathrm{w} \%$ is coded as EVAx in this paper. The parameters of each grade EVA are shown in Table 1. Behenamide (analytical standard) as a nucleating agent was purchased from Fluka. All the materials were used as received.

Table 1. Characteristics of EVA copolymers

\begin{tabular}{|l|c|c|c|c|}
\hline $\begin{array}{c}\text { Sample } \\
\text { code }\end{array}$ & $\begin{array}{c}\text { VA content } \\
{[\mathbf{w t} \%]}\end{array}$ & $\begin{array}{c}\text { Mooney viscosity } \\
\mathbf{M L}\left(\mathbf{1 + 4 )} \mathbf{1 0 0}^{\circ} \mathbf{C}\right. \\
{[\mathbf{M U}]}\end{array}$ & $\begin{array}{c}\text { Density } \\
{\left[\mathbf{k g} / \mathbf{m}^{\mathbf{3}}\right]}\end{array}$ & $\begin{array}{c}\mathbf{T}_{\mathbf{g}}^{\mathbf{b}} \\
{\left[{ }^{\circ} \mathbf{C}\right]}\end{array}$ \\
\hline EVA40 & $40 \pm 1.5$ & $20 \pm 4$ & 980 & -32 \\
\hline EVA50 & $50 \pm 1.5$ & $27 \pm 4$ & 1000 & -29 \\
\hline EVA60 & $60 \pm 1.5$ & $27 \pm 4$ & 1040 & -28 \\
\hline EVA70 & $70 \pm 1.5$ & $27 \pm 4$ & 1080 & -20 \\
\hline EVA90 & $90 \pm 2.0$ & $38 \pm 6$ & 1150 & 14 \\
\hline
\end{tabular}

${ }^{a}$ Tested according to IS289/ASTM D 1646.

${ }^{b}$ Measured by DSC at a heating rate of $10^{\circ} \mathrm{C} / \mathrm{min}$.

\subsection{Blend preparation}

The PHBM and EVA copolymers were dried at $50^{\circ} \mathrm{C}$ in a vacuum oven for 12 hours before use. PHBM/ EVA blends with $0.5 \mathrm{wt} \%$ of behenamide based on the weight of PHBM were prepared in a twin-screw mini-extruder at $170^{\circ} \mathrm{C}$ for $3 \mathrm{~min}$. The speed of screw was $90 \mathrm{rpm}$.

Two series of blends were studied:

- PHBM/EVA (80/20, wt/wt) blends with varying the VA content in EVA copolymers from 40 to $90 \mathrm{wt} \%$;

- PHBM/EVA90 blends with compositions of $100 / 0,90 / 10,80 / 20,70 / 30,50 / 50,30 / 70$ and $0 / 100(\mathrm{wt} / \mathrm{wt})$.

The extrudates of PHBM/EVA blends were compression-molded into sheets ( $0.6 \mathrm{~mm}$ in thickness) at $175^{\circ} \mathrm{C}$ for $2 \mathrm{~min}$ and then cold compression- 
molded for $15 \mathrm{~min}$. The compression-molded samples were used for further characterizations. It has to be addressed that the degradation of PHBM/EVA blends under the above processing conditions were not so serious as evidenced by a relatively stable torque values of the mini-extruder as a function of processing time.

\subsection{Characterizations}

Scanning electron microscope (SEM): SEM (Quanta 600-F-ESEM, FEI, the Netherlands) was used to characterize the phase morphology of the PHBM/ EVA blends. The samples were first cryo-microtomed at $-80^{\circ} \mathrm{C}$ with a diamond knife and then sputtercoated with a thin gold layer at $65 \mathrm{~mA}$ for $45 \mathrm{sec}-$ onds before observation.

Transmission electron microscope (TEM): TEM was performed on the PHBM/EVA90 (80/20, wt/wt) samples using a Tecnai 20 microscope, operated at $200 \mathrm{kV}$. Ultrathin sections $(\sim 100 \mathrm{~nm})$ were prepared at $-80^{\circ} \mathrm{C}$ using a Leica Ultracut S/FCS microtome. No staining was applied because PHBM and EVA copolymers have enough electron density contrast according to our previous study.

Two types of mechanical behavior were studied at room temperature:

- Universal tensile properties of the samples were measured by using a Zwick Z100 tensile tester at a crosshead speed of $10 \mathrm{~mm} / \mathrm{min}$. The narrow parallel-sided portion of the dumbbell-shaped tensile bar was $12 \mathrm{~mm}$ in length, $0.6 \mathrm{~mm}$ in thickness and $2 \mathrm{~mm}$ in width.

- Hysteresis cycle tests were performed on the same tensile tester. The dumbbell-shaped tensile bar was first stretched to $500 \%$ elongation with no hold time imposed at extension, after which the crosshead direction was immediately reversed to $170 \%$ elongation. The cross-head speed of stretching and recovering is $10 \mathrm{~mm} / \mathrm{min}$. Three repeating cycles were tested.

Dynamic mechanical analysis (DMA): DMA was carried out on a DMAQ800 (TA Instruments, USA) with a tensile-film mode. The specimens $(13.0 \times 6.5 \times$ $0.6 \mathrm{~mm}^{3}$ ) were measured from -60 to $170^{\circ} \mathrm{C}$ at a frequency of $1 \mathrm{~Hz}$, with a constant amplitude of $10 \mu \mathrm{m}$ and a temperature ramp of $3{ }^{\circ} \mathrm{C} / \mathrm{min}$. The storage modulus and loss modulus were recorded as a function of temperature.

Differential scanning calorimetry (DSC): DSC analysis is performed on a DSC Q1000 (TA Instruments,
USA). The samples were heated from -50 to $190^{\circ} \mathrm{C}$. The first heating DSC scans were recorded and the glass transition temperatures $\left(T_{\mathrm{g}}\right)$ were obtained from the first heating DSC curves.

Polarized optical microscope (POM): Thin films of PHBM/EVA blends were cryo-microtomed from the compression-molded sheets. The spherulite morphology of each film was observed by using a Zeiss LM Axioplan microscope under polarization mode. The spherulite growth rate $(G)$ of PHBM was measured by using the microscope in combination with a Linkam hot stage. Thin film of each sample was first heated to $190^{\circ} \mathrm{C}$ to erase thermal history, then quenched to designed temperatures, i.e. $70-130^{\circ} \mathrm{C}$ at a cooling rate of $60^{\circ} \mathrm{C} / \mathrm{min}$, and kept at the designed temperatures for isothermal crystallization. The radii of the spherulites $(r,[\mu \mathrm{m}])$ were recorded as a function of time $(t,[\mathrm{~min}])$. The spherulite growth rate $(G)$ was obtained via equation $G=\Delta r / \Delta t$.

\section{Results and discussion}

\subsection{Effect of VA content on the miscibility and morphology of PHBM/EVA blends}

A first insight in miscibility and phase separation of two (co-)polymers is comparing their solubility parameters $(\delta)$. Two polymers may show miscible behavior if their solubility parameters are close to each other. An example is about poly(vinyl acetate) (PVAc) and PHBM whose solubility parameters are 9.6 and $9.1\left(\mathrm{cal} / \mathrm{cm}^{3}\right)^{1 / 2}$ respectively [20]. The solubility parameters of the EVA copolymers vary between the $\delta$ of LDPE $\left(8.3\left(\mathrm{cal} / \mathrm{cm}^{3}\right)^{1 / 2}[20]\right.$ and the $\delta$ of PVAc depending on composition. Thus, the miscibility between PHBM and EVA could be tuned by varying composition of the EVA copolymers.

The miscibility of polymers can be indicated by analysis of the glass transition temperatures $\left(T_{\mathrm{g}}\right)$ in their blends. The storage modulus $\left(E^{\prime}\right)$ and loss modulus $\left(E^{\prime \prime}\right)$ of the PHBM/EVA blends from dynamic mechanical analysis (DMA) are presented in Figure 1. The peak temperatures of the $E^{\prime \prime}$ are referred to as $T_{\mathrm{g}}$ of the corresponding components. The neat PHBM and the PHBM/EVA90 (80/20, wt/wt) blend show single $T_{\mathrm{g}}$ of -1.3 and $8.3^{\circ} \mathrm{C}$ respectively. Each of the other samples displays two separate $T_{\mathrm{g}}$, one for the PHBM phase $\left(T_{\mathrm{g}-\mathrm{PHBM}}\right)$ and the other for the EVA phase $\left(T_{\text {g-EVA }}\right)$, as noted in Figure 1. The glass transition temperatures of the PHBM/EVM90 blends were investigated as a function of EVA90 content, as shown in Figure 2. Only single $T_{\mathrm{g}}$ is detected for 


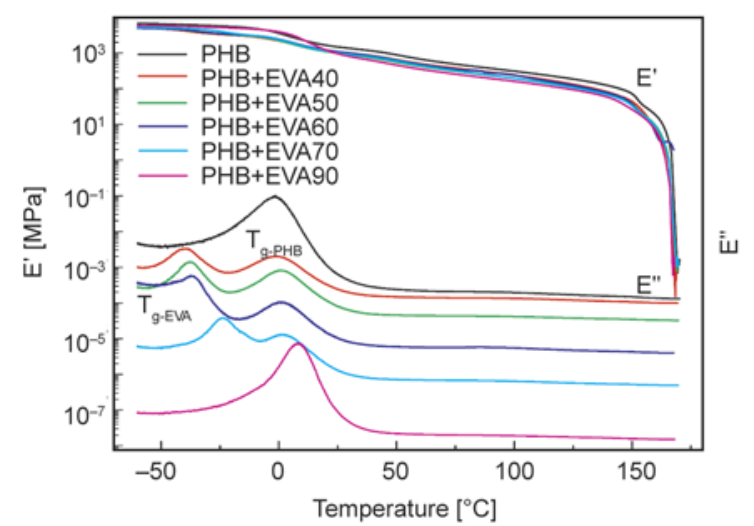

Figure 1. Storage modulus $\left(E^{\prime}\right)$ and loss modulus $\left(E^{\prime \prime}\right)$ of the PHBM and the PHBM/EVA (80/20, wt/wt) blends. The $E^{\prime \prime}$ curves were shifted in the $y$ axis to avoid overlaps.

each PHBM/EVA90 blend. Moreover, the $T_{\mathrm{g}}$ shows strong dependence on compositions. These results indicate that PHBM is thermodynamically miscible with EVA90 but is immiscible with the other EVA

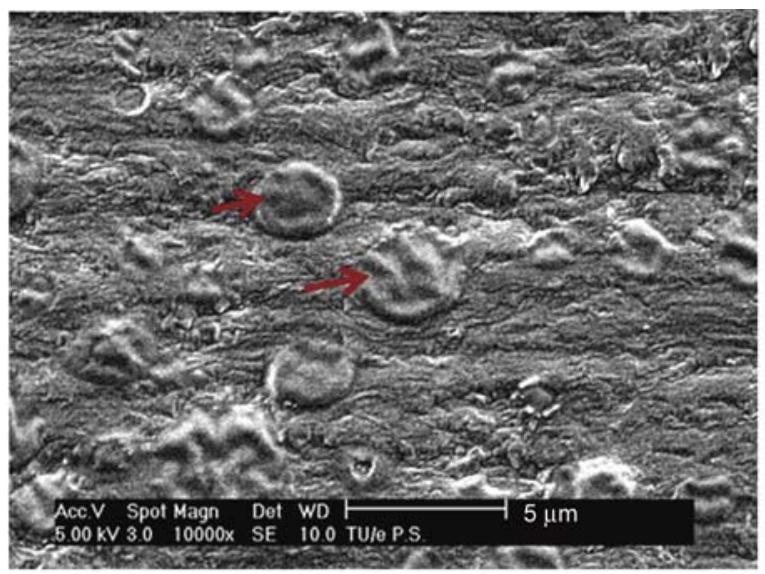

a)

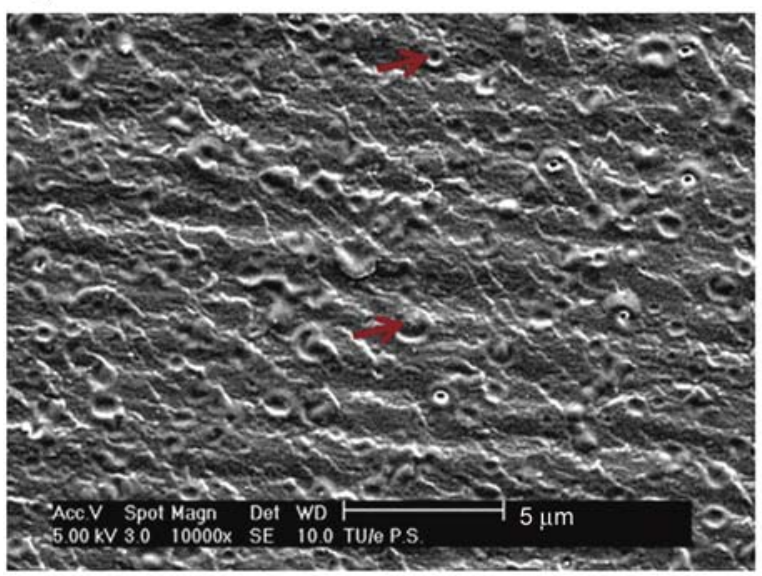

c)

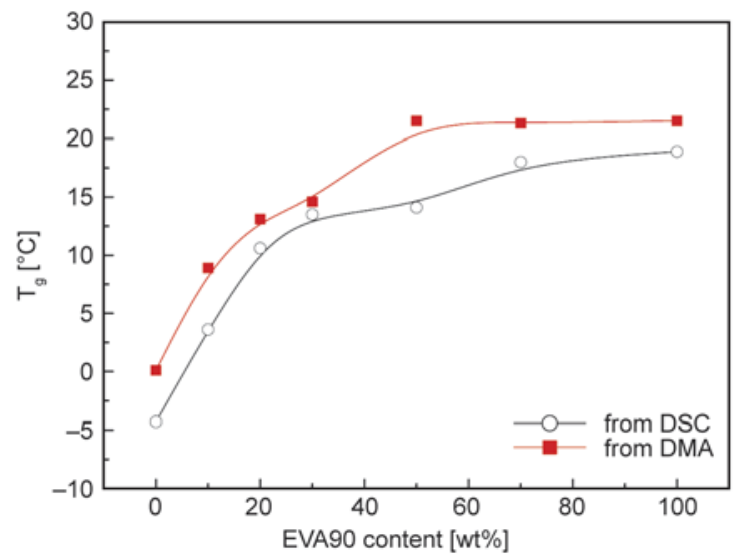

Figure 2. Glass transition temperatures $\left(T_{\mathrm{g}}\right)$ of the PHBM/ EVA90 blends as a function of EVA90 contents. The $T_{\mathrm{g}}$ is measured by using DSC and DMA respectively

copolymers. The values and variation trend of the storage modulus $\left(E^{\prime}\right)$ of the PHBM are slightly affected by addition of $20 \mathrm{wt} \%$ of the EVA copolymers since PHBM is a matrix.

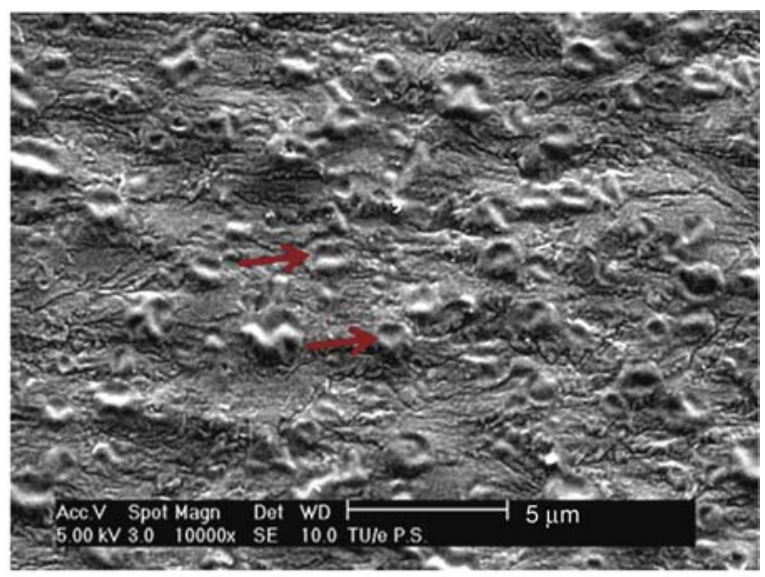

b)

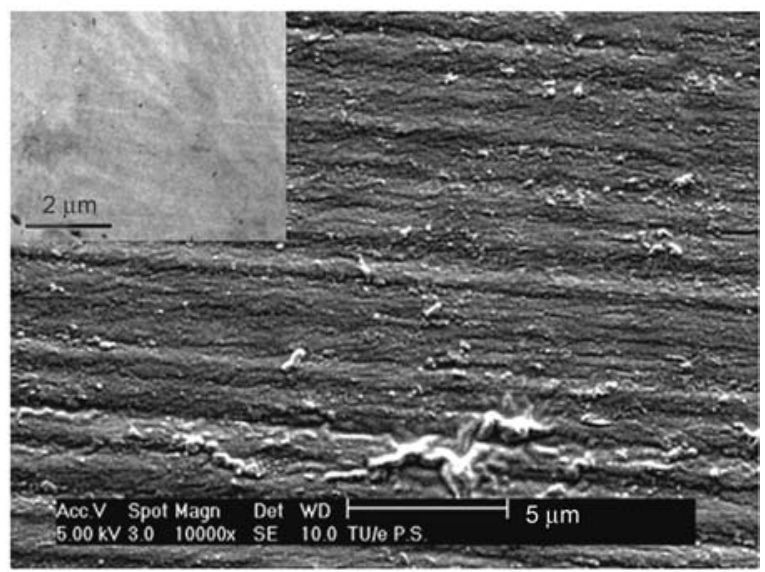

d)

Figure 3. SEM images (scale bar $=5 \mu \mathrm{m}$ ) of the PHBM/EVA $(80 / 20$, wt/wt) blends as a function of VA contents: (a) $40 \mathrm{wt} \%$, (b) $50 \mathrm{wt} \%$, (c) $70 \mathrm{wt} \%$ and (d) $90 \mathrm{wt} \%$. The EVA domains are indicated by arrays in PHBM matrix. The slight orientation of the morphology in these images is resulted from section-preparation (microtome). A TEM image of the PHBM/EVA90 (80/20, wt/wt) is shown as an inset in image d. 
The morphology of PHBM/EVA (80/20) blends as a function of VA content is shown in Figure 3. Phase separation occurs between the PHBM and EVA when VA content is less than $70 \mathrm{wt} \%$, indicating an immiscible feature. Since the vinyl acetate segments are miscible with the PHBM matrix, [19] the interfacial properties of the PHBM/EVA blends are improved with an increase in VA content. The particle size of the EVA40 in the blend is relatively large $(\sim 3 \mu \mathrm{m})$ being ascribed to a high interfacial tension. The EVA particle size is decreased to $\sim 1 \mu \mathrm{m}$ with increasing the VA content to $70 \mathrm{wt} \%$ (Figure 3a-3c). On the other hand, no phase separation is observed in the PLA/EVA90 blend (Figure 3d) as they are miscible. It has to be remarked that heterogeneities and oriented pattern on the PHBM/EVA90 surface (Figure 3d) are caused in sample preparation (microtome) process. The single-phase morphology of the $\mathrm{PHBM} / \mathrm{EVA} 90$ blend is further confirmed by TEM characterization as shown by the inset in Figure 3d.

\subsection{Effect of VA content on the mechanical properties of PHBM/EVA blends}

Miscibility and morphology are crucial to mechanical properties of a polymer blend. Tensile properties of the PHBM/EVA (80/20, wt/wt) blends as a function of VA content are investigated and shown in Figure 4. All the blends show yielding behavior during tensile test. The maximum tensile strength $\left(\sigma_{\mathrm{m}-\mathrm{t}}\right)$ of the blends increases gradually with the VA content. The highest $\sigma_{\mathrm{m}-\mathrm{t}}(30 \mathrm{MPa})$ and elongation at break $\left(\varepsilon_{b}=150 \%\right)$ are obtained at the VA content of $90 \mathrm{wt} \%$. The $E$-modulus of the blends varies between 600 and $800 \mathrm{MPa}$ when the VA content increases from 40 to $90 \mathrm{wt} \%$, as shown in Figure $4 \mathrm{~b}$. Neat PHBM is rigid with $\sigma_{\mathrm{m}-\mathrm{t}}$ and $\varepsilon_{\mathrm{b}}$ of $36 \mathrm{MPa}$ and $5.6 \%$

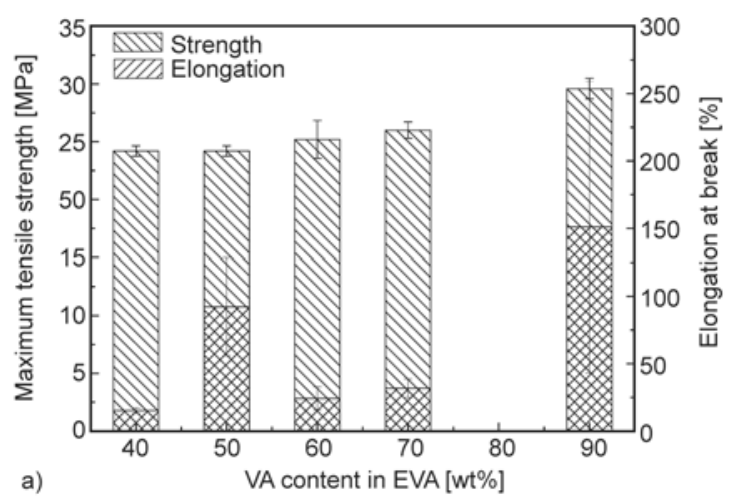

respectively (see Figure 5), thus the ductility of PHBM was improved by addition of $20 \mathrm{wt} \%$ EVA.

\subsection{Mechanical properties of PHBM/EVA90 blends}

EVA90 is the most promising among the studied EVA grades in improving mechanical properties of PHBM (Figure 4), therefore the mechanical behavior of the PHBM/EVA90 blends are investigated in detail, as shown in Figure 5.

The stress-strain curves of the PHBM/EVA90 blends are shown in Figure 5a. EVA90 shows typical stressstrain behavior of an elastomer. In contrast, PHBM is brittle with high tensile stress and low elongation at break. It fractures without yielding (Figure 5a curve 1). The PHBM/EVA90 (80/20, wt/wt) shows strong strain-softening followed by a weak strainhardening. Consequently this blend breaks at relatively low elongation, as shown in Figure 5a curve 2. Strain-softening is an indication of strain localization. If the strain cannot be delocalized brittle fracture would occur. It is known that strain can be delocalized via strain-hardening resulting in tough materials [21]. The strain-softening behavior becomes less pronounced with increasing the EVA90 content up to $70 \mathrm{wt} \%$, while the strain-hardening becomes more pronounced. As a consequence, the blends with high EVA90 content behave as thermoplastic elastomers (TPE) or thermoplastic vulcanizates (TPV) [22].

Figure $5 \mathrm{~b}$ shows the yield stress $\left(\sigma_{\mathrm{y}}\right)$ and yield strain $\left(\varepsilon_{\mathrm{y}}\right)$ of the PHBM/EVA90 blends. The $\sigma_{\mathrm{y}}$ decreases monotonically with increasing EVA90 content accompanied by an increase in $\varepsilon_{\mathrm{y}}$ indicating an enhanced ductility. The $\sigma_{\mathrm{m}-\mathrm{t}}$ and $\varepsilon_{\mathrm{b}}$ of the blends (Figure 5c) show similar trends as the $\sigma_{\mathrm{y}}$ and $\varepsilon_{\mathrm{y}}$ respectively. Remarkably, the $\varepsilon_{\mathrm{b}}$ of the PHBM is

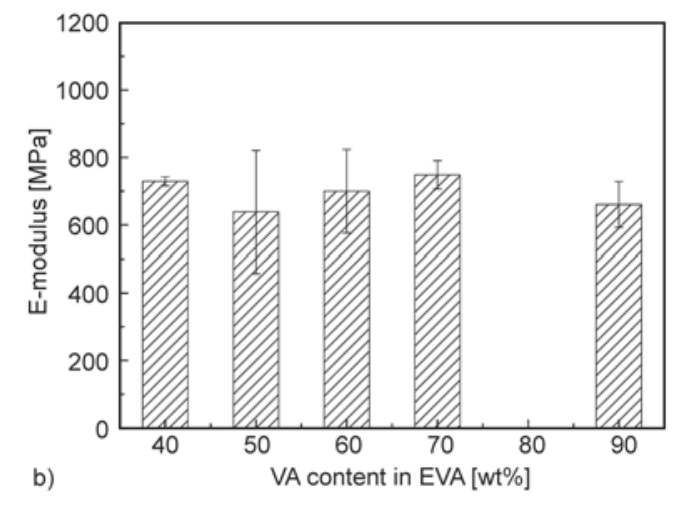

Figure 4. Tensile properties of the PHBM/EVA (80/20,wt/wt) blends as a function of VA contents. (a) maximum tensile strength and elongation at break and (b) $E$-modulus. 

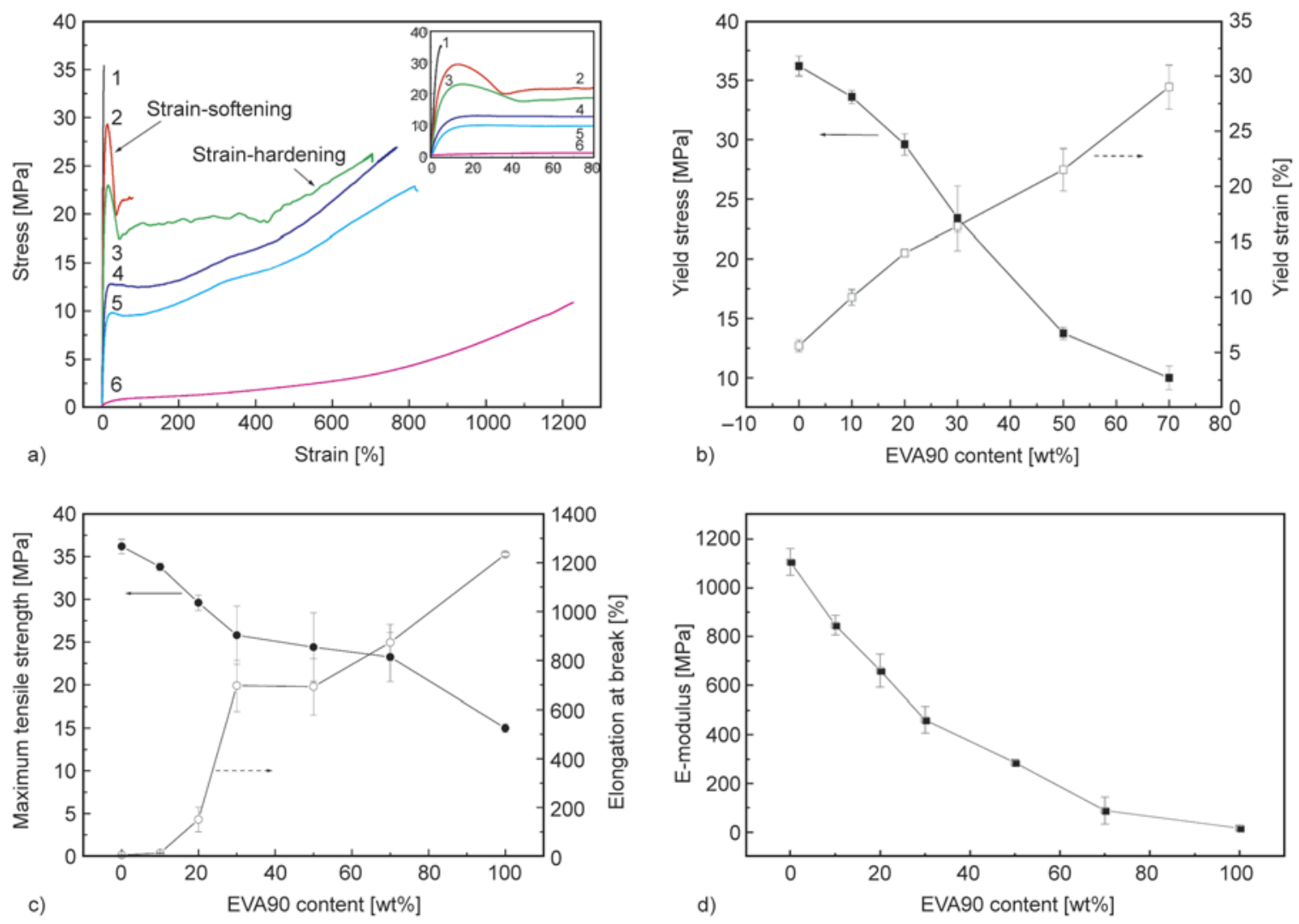

Figure 5. Mechanical behaviour of the PHBM/EVA90 blends as a function of EVA90 contents. (a) stress-strain curves, (b) yield stress and yield strain, (c) maximum tensile strength and elongation at break and (d) $E$-modulus. The stress-strain curves of 1-6 in Figure 5a correspond to the PHBM/EVA90 blends with the EVA90 content of 0, 20, $30,50,70$ and $100 \mathrm{wt} \%$ respectively, and the initial stage of the stress-strain curves is inset in Figure 5a to clarify the yielding behavior of the samples.

increased by a factor of more than 140 after addition of $30-50 \mathrm{wt} \%$ of the EVA90. Meanwhile, the $\sigma_{\mathrm{m}-\mathrm{t}}$ is much higher than the $\sigma_{\mathrm{y}}$, notably at high EVA90 content because of the pronounced strainhardening. In addition, $E$-modulus of the blends decreases with increasing the EVA90 content, as shown in Figure $5 \mathrm{~d}$. These results display elastic behavior of the PHBM/EVA90 blends.

\subsection{Strain-recovery behavior of PHBM/EVA90 blends}

The PHBM/EVA90 blends show high and fast strainrecovery within a short time ( $>60 \%$ within $4 \mathrm{~min})$, as demonstrated in Figure 6. The strain-recovery feature remains in the repeating cycles. These results indicate good elasticity and rubbery characters of the blends. Meantime, the PHBM/EVA90 blends exhibit notable stress-strain hysteresis which is a characteristic feature of thermoplastic elastomers [23] The lower content of the EVA90 the more remarkable hysteresis. It is also noticed that the hysteresis mainly occurs in the first hysteresis stress-strain cycle since the second and third cycles are close to each other (the $3^{\text {rd }}$ cycle is not shown here to make the curves more readable). EVA90 shows very similar strainrecovery behavior as the blends (Figure 6d). Hence, the existence of EVA90 might be one of the key reasons for the elastic behavior of the PHBM/EVA90 blends.

\subsection{Mechanism of the thermoplastic elasticity of PHBM/EVA90 blends}

Heterogeneities are needed for toughness of polymers while crosslink is required for elasticity. As discussed above, the PHBM/EVA90 blends show typical thermoplastic elasticity. However, neither heterogeneities nor chemical crosslinks exist in the blends. It thus would be of interest to reveal the mechanism of the thermoplastic elasticity of the blends.

A typical route to make TPE is by blending a plastic with an immiscible rubber in combination with dynamic crosslinking. [24-26] In such process the rubber phase is crosslinked and re-dispersed in the 

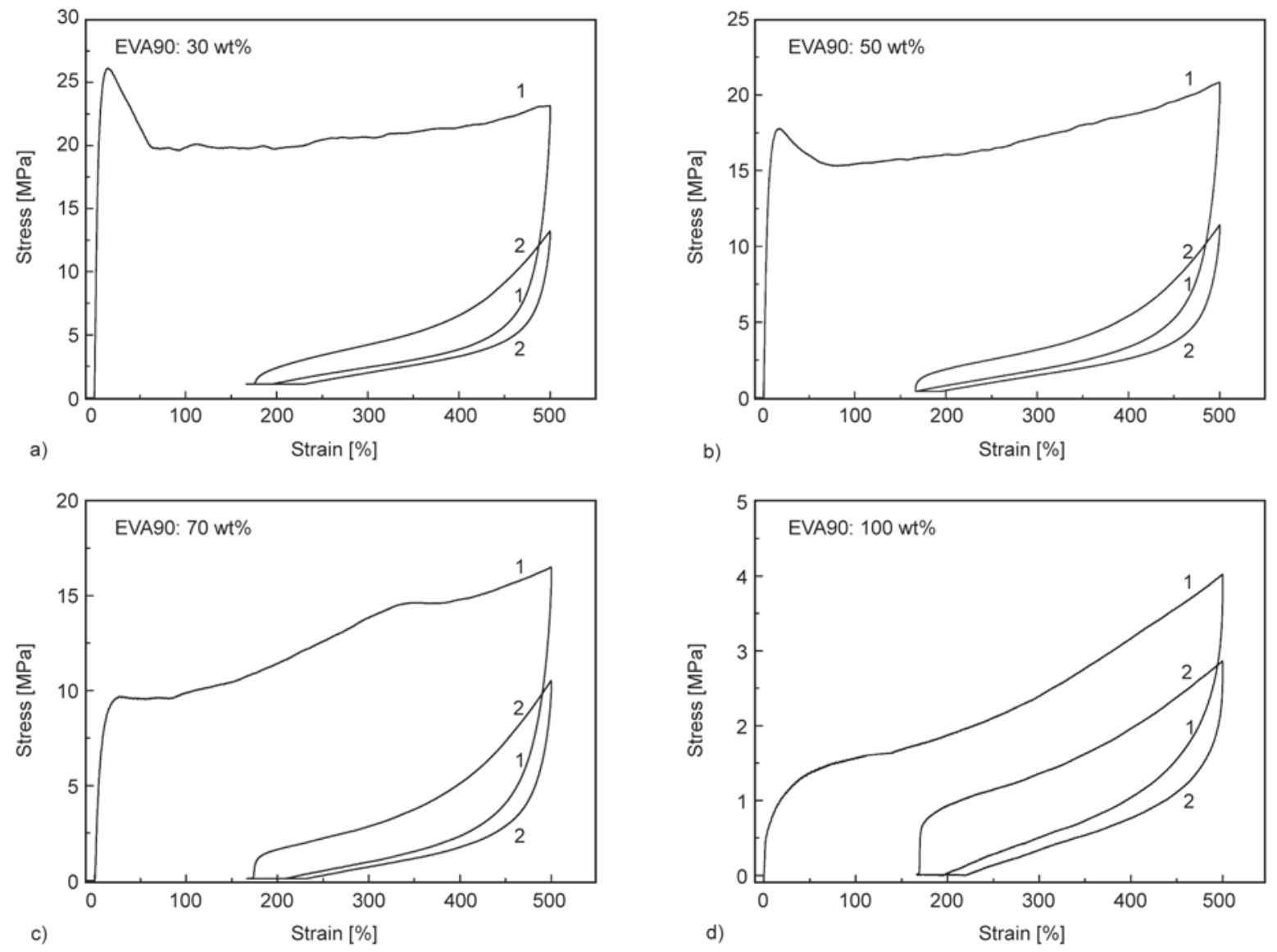

Figure 6. Hysteresis stress-strain curves of the PHBM/EVA90 blends as a function of EVA90 contents: (a) $30 \mathrm{wt} \%$, (b) $50 \mathrm{wt} \%$, (c) $70 \mathrm{wt} \%$ and (d) $100 \mathrm{wt} \%$. The $1^{\text {st }}$ and $2^{\text {nd }}$ cycles are indicated by Arabic numerals in the figures.

plastic phase. The re-dispersed rubber phase interconnects leading to good elastic properties and the properties are affected by rubber particle size, e.g. TPE (or TPV) from poly(propylene)/ethylene-propylene-diene rubber blends [22]. The other route to prepare TPE is by making block copolymers containing both soft and hard segments, e.g. thermoplastic poly(urethane) (TPU) and styrene-b-butadiene-bstyrene copolymers (SBS) [27, 28].

PHBM is a brittle semi-crystalline thermoplastic. The brittleness of PHBM is ascribed to large spherulites and cracks in the spherulites [5]. Therefore, the crystallization behavior (e.g. morphology and crystallinity) is important to its mechanical properties. In this study, the crystallization of PHBM in the blends was complete since no cold crystallization peaks were detected from the first heating DSC curves, as shown in Figure 7. The crystallinity $\left(X_{\mathrm{c}}\right)$ of PHBM is around $38 \%$ in the samples (Figure 8) calculated via equation $X_{\mathrm{c}}=\Delta H_{\mathrm{m}} /\left(\Delta H_{0} \cdot W\right) \cdot 100 \%$, where $\Delta H_{0}$ is the melt enthalpy of $100 \%$ crystalline PHB (146.6 J/g) [29], $\Delta H_{\mathrm{m}}$ is the measured melt enthalpy of PHBM in the blends, $W$ is the weight fraction of the PHBM in the blends. Although the $X_{\mathrm{c}}$ of PHBM was similar in different samples, the crystallization kinetics, crystal morphology and the $X_{\mathrm{c}}$ of the blends (obtained via equation $X_{\mathrm{c}}=$ $\left.\Delta H_{\mathrm{m}} / \Delta H_{0} \cdot 100 \%\right)$ show strong dependence on the compositions.

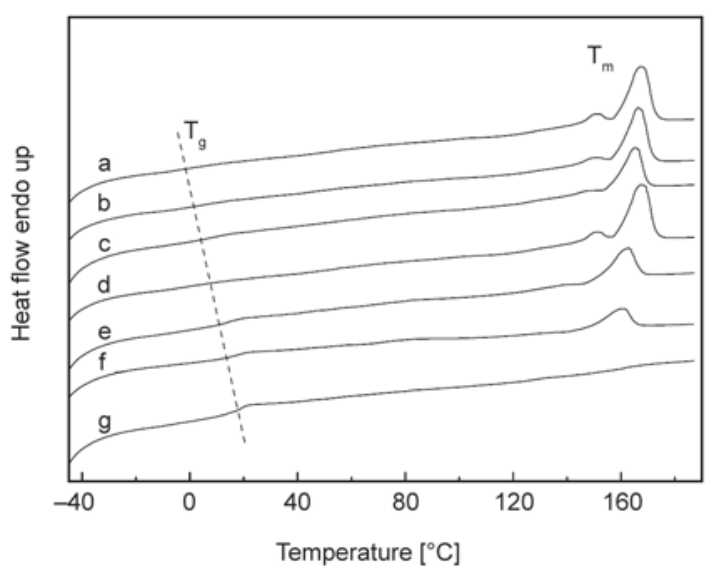

Figure 7. The first heating DSC curves of the PHBM/EVA90 blends as a function of EVA90 contents: (a) $0 \mathrm{wt} \%$, (b) $10 \mathrm{wt} \%$, (c) $20 \mathrm{wt} \%$, (d) $30 \mathrm{wt} \%$, (e) $50 \mathrm{wt} \%$, (f) $70 \mathrm{wt} \%$ and (g) $100 \mathrm{wt} \%$ 


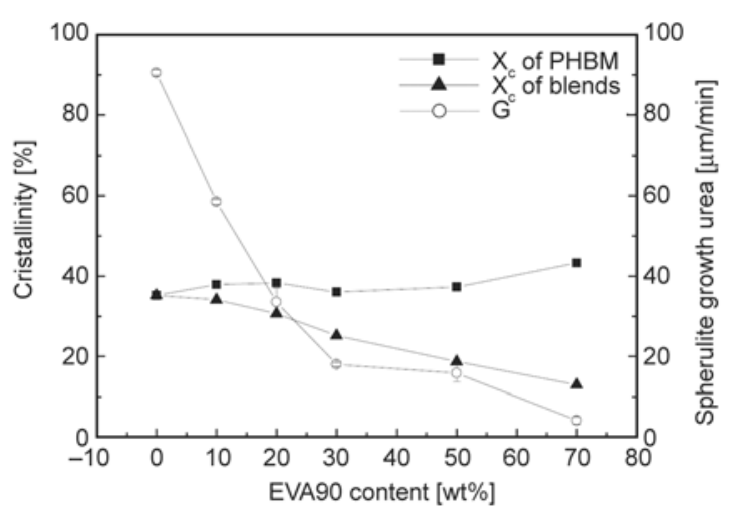

Figure 8. Crystallinity $\left(X_{\mathrm{c}}\right)$ of the PHBM and the PHBM/ EVA90 blends and spherulite growth rate $(G)$ of the PHBM as a function of EVA90 contents. The $G$ presented in Figure 8 was measured at $90^{\circ} \mathrm{C}$ while it shows similar trend at other temperatures (not shown here).

It was reported that crystallization kinetics of PHB were slowed down by addition of miscible PVAc. [19]. Similar behavior was observed in the PHBM/ EVA90 blends e.g., the spherulite growth rate $(G)$ of the PHBM decreases with increasing the EVA90 content, as shown in Figure 8. As a result, the spherulite morphology of the PHBM/EVA90 blends was improved by addition of the EVA90, which was studied by using polarized optical microscope (POM), as shown in Figure 9.

Large spherulites $(\sim 150 \mu \mathrm{m})$ with cracks are observed in neat PHBM (Figure 9a) resulting in brittleness of the PHBM. The spherulite size was reduced to $50-100 \mu \mathrm{m}$ after addition of $10-20 \mathrm{wt} \%$ of the EVA90, leading to a notable improvement in the toughness. Due to the decrease in $G$ and the presence of nucleating agents, a large number of spherulites with sub- $\mu \mathrm{m}$ dimensions are uniformly dispersed in the PHBM/EVA90 blends when the EVA90 content is higher than $30 \mathrm{wt} \%$ (Figures 9d, $9 \mathrm{e}$ and $9 \mathrm{f})$. Such morphology is associated with the above discussed thermoplastic elastomeric properties. The EVA90 molecules are diluted in the PHBM matrix when the EVA90 content is lower than $20 \mathrm{wt} \%$, whereas the EVA90 molecules may interentangle at high content $(>30 \mathrm{wt} \%)$ in the blends. Since the EVA90 is amorphous and rubbery (Figure $9 \mathrm{~g}$ and Figure 5a), it exists as random coil in the amorphous region of the blends, i.e. between PHBM lamellae and between spherulites. The lamellae and fine spherulites play a role of physical crosslink points of the amorphous PHBM and the rubbery EVA90 molecules resulting in a thermoreversible network. The network is schematically illustrated in Figure 10a. The stress under deformation can be delocalized by stretching the random coils and the physical network (Figure 10b), thus toughness and ductility of the blends are obtained. The deformation can be recovered to a high degree when the stress is removed because random coil is the favorable state of the rubbery molecules, as illustrated in Figure 10a10b. Consequently, this special structure results in high elasticity of the PHBM/EVA90 blends. Another advantage is that the blends are easily processable after melting and show elastic behavior after crystallization, as illustrated in Figure 10a-10c.

\section{Conclusions}

The properties of poly(hydroxyalkanoate)s (PHBM, Metabolix) were modified by poly(ethylene-co-vinyl acetate) (EVA) using a melt-blending technique. The miscibility between the PHBM and EVA were studied via thermal analysis (DMA and DSC) and microscopy (SEM and TEM). The PHBM is immiscible with EVA at VA content lower than $70 \mathrm{wt} \%$, while is miscible with EVA90 which contains $90 \mathrm{wt} \%$ of VA. The effect of VA content on the mechanical properties of the PHBM/EVA $(80 / 20$, $\mathrm{wt} / \mathrm{wt}$ ) blends was studied. The PHBM/EVA90 $(80 / 20, w t / w t)$ blend shows higher maximum tensile strength $\left(\sigma_{\mathrm{m}-\mathrm{t}}\right)$ and larger elongation at break $\left(\varepsilon_{\mathrm{b}}\right)$ than the others. PHBM is brittle and stiff with high $\sigma_{\mathrm{m}-\mathrm{t}}$ and low $\varepsilon_{\mathrm{b}}$. It is toughened by $20 \mathrm{wt} \%$ of the EVA90 showing notable stress yielding and high elongation at break. Interestingly, thermoplastic elastomeric behavior of the PHBM/EVA90 blends was achieved when the EVA90 content is higher than $30 \mathrm{wt} \%$, i.e., high $\varepsilon_{\mathrm{b}}(>800 \%)$, good strain-recovery and moderate $E$-modulus ( $<500 \mathrm{MPa})$. The thermoplastic elastomeric properties of the PHBM/EVA90 blends are associated with their structures. Crystallization of the PHBM occurred in the PHBM/EVA90 blends upon cooling. Since the EVA90 is thermodynamically miscible with the PHBM it exists among the PHBM crystals (lamellae and spherulites). Moreover the spherulite growth rate of PHBM is reduced in the presence of EVA90 which results in small spherulite size but large in numbers. Consequently the PHBM crystals, e.g. the large number of fine spherulites act as crosslink points leading to a physical network in the blends. The physical network and elastic EVA90 molecules are considered to be responsible for the thermoplastic elastomeric prop- 


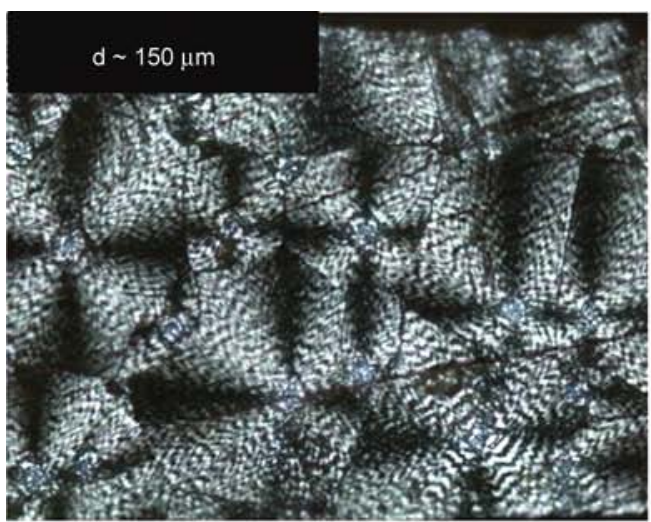

a)

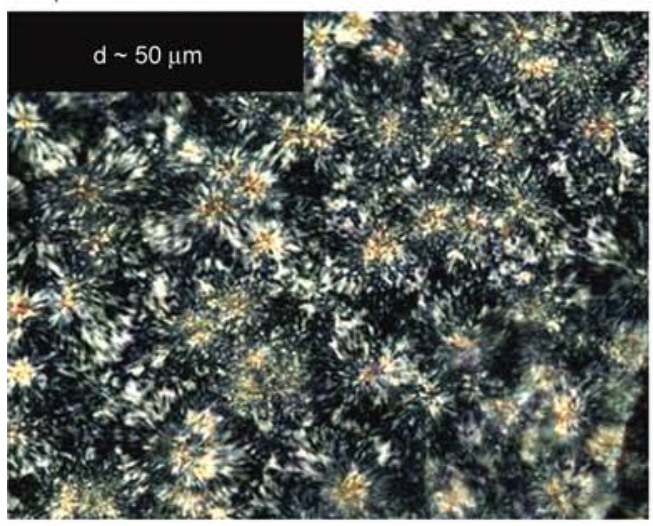

c)

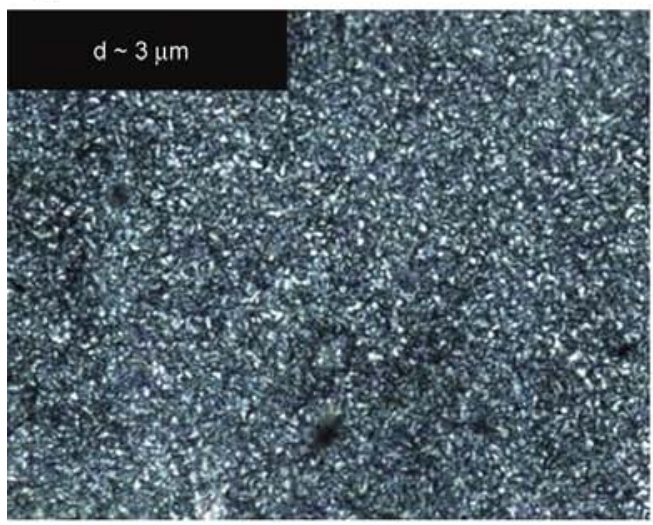

e)

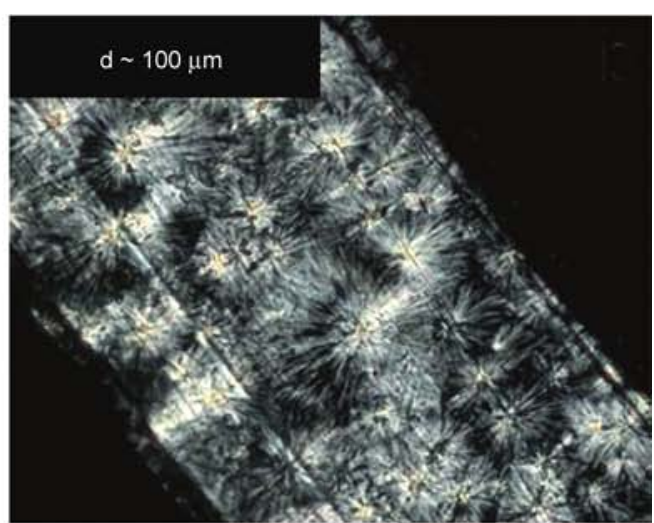

b)

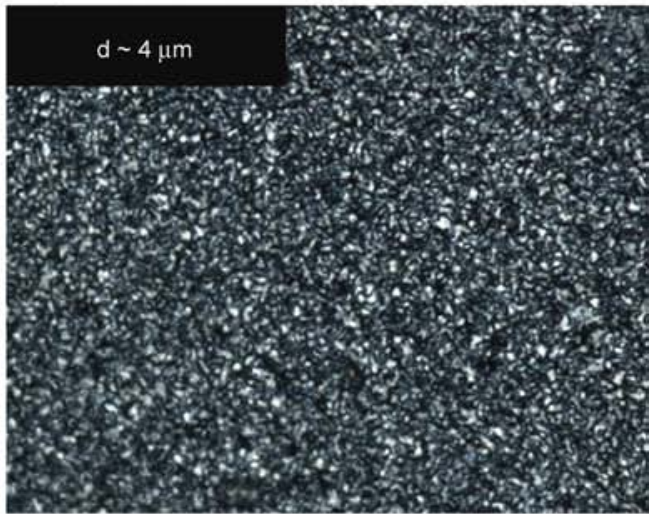

d)

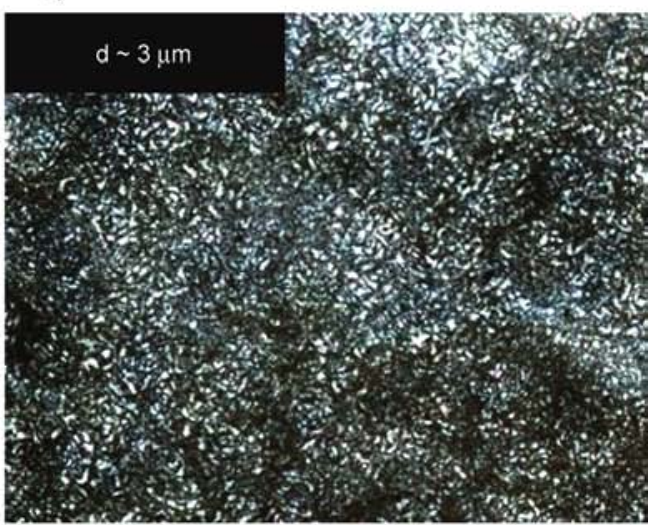

f)

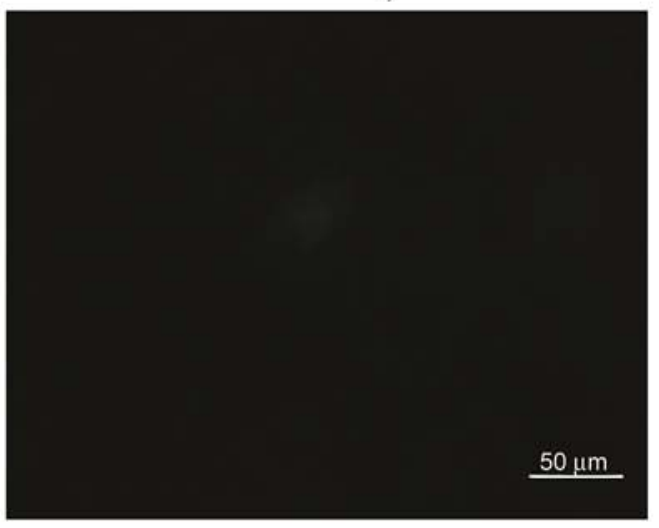

g)

Figure 9. Polarized optical microscope images (scale bar $=50 \mu \mathrm{m}$, same magnification) of the PHBM/EVA90 blends as a function of EVA90 contents: (a) $0 \mathrm{wt} \%$, (b) $10 \mathrm{wt} \%$, (c) $20 \mathrm{wt} \%$, (d) $30 \mathrm{wt} \%$, (e) $50 \mathrm{wt} \%$, (f) $70 \mathrm{wt} \%$ and (g) $100 \mathrm{wt} \%$. The images were taken from compression molded samples. The average spherulite size is shown on the top left of each image. 


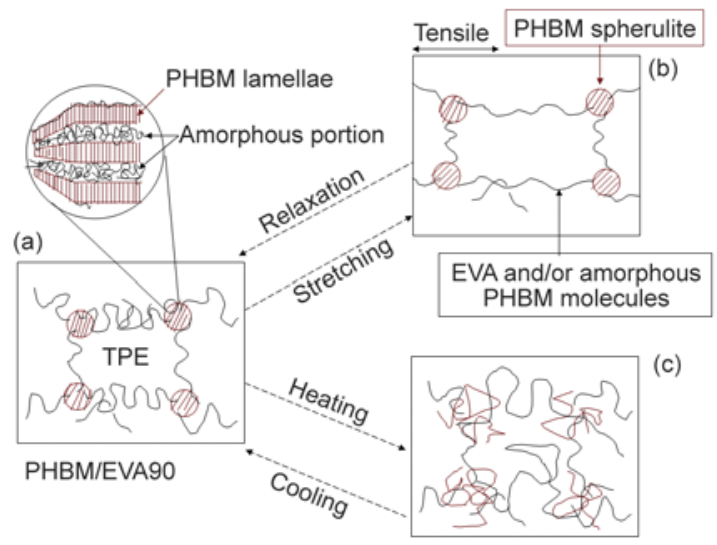

Figure 10. Schematic illustration of micro-structures of the PHBM/EVA90 blends in different states: (a) solid static state, (b) stretched state and (c) melt state. (a)-(b) shows the elastic behavior while (a)(c) shows the thermoplastic behavior.

erties. Therefore, a new class of partially bio-based thermoplastic elastomers (bio-TPE) is designed and prepared which has potential application in substitution of conventional TPE materials.

\section{Acknowledgements}

This work is supported by the National Natural Science Foundation of China $(51303067,51173072)$ and the Natural Science Foundation of Jiangsu Province (BK20130147). The authors acknowledge P. Schmit and A.B. Spoelstra from Eindhoven University of Technology in the Netherlands for valuable discussions on the morphology characterization and acknowledge Lanxess Chemical Co., Ltd. for kindly providing EVA (Levapren ${ }^{\circledR}$ EVM) materials.

\section{References}

[1] Saito Y., Doi Y.: Microbial synthesis and properties of poly(3-hydroxybutyrate-co-4-hydroxybutyrate) in Comamonas acidovorans. International Journal of Biological Macromolecules, 16, 99-104 (1994).

DOI: 10.1016/0141-8130(94)90022-1

[2] Rodríguez-Contreras A., Koller M., Dias M. M. D.: Calafell-Monfort M., Braunegg G., Marqués-Calvo M. S.: High production of poly(3-hydroxybutyrate) from a wild Bacillus megaterium Bolivian strain. Journal of Applied Microbiology, 114, 1378-1387 (2013). DOI: $10.1111 / \mathrm{jam} .12151$

[3] Lemoigne M.: Assay of poly- $\beta$-hydroxybutyric acid. Bulletin de la Societe de Chimie Biologique, 8, 770782 (1926).

[4] Sudesh K., Abe H., Doi Y.: Synthesis, structure and properties of polyhydroxyalkanoates: Biological polyesters. Progress in Polymer Science, 25, 1503-1555 (2000).

DOI: $10.1016 / \mathrm{S} 0079-6700(00) 00035-6$
[5] Hobbs J. K., McMaster T. J., Miles M. J., Barham P. J.: Cracking in spherulites of poly(hydroxybutyrate). Polymer, 37, 3241-3246 (1996). DOI: 10.1016/0032-3861(96)88468-0

[6] Ma P., Hristova-Bogaerds D. G., Lemstra P. J., Zhang Y., Wang S.: Toughening of PHBV/PBS and PHB/PBS blends via in situ compatibilization using dicumyl peroxide as a free-radical grafting initiator. Macromolecular Materials and Engineering, 297, 402-410 (2012). DOI: $10.1002 /$ mame.201100224

[7] Tanadchangsaeng N., Yu J.: Miscibility of natural polyhydroxyalkanoate blend with controllable material properties. Journal of Applied Polymer Science, 129, 2004-2016 (2013).

DOI: $10.1002 / a p p .38906$

[8] Madden L. A., Anderson A. J., Asrar J.: Synthesis and characterization of poly(3-hydroxybutyrate) and poly(3hydroxybutyrate-co-3-hydroxyvalerate) polymer mixtures produced in high-density fed-batch cultures of Ralstonia eutropha (Alcaligenes eutrophus). Macromolecules, 31, 5660-5667 (1998).

DOI: $10.1021 / \mathrm{ma9} 80606 \mathrm{w}$

[9] Doi Y., Kitamura S., Abe H.: Microbial synthesis and characterization of poly(3-hydroxybutyrate-co-3-hydroxyhexanoate). Macromolecules, 28, 4822-4828 (1995). DOI: 10.1021/ma00118a007

[10] Parulekar Y., Mohanty A. K.: Biodegradable toughened polymers from renewable resources: Blends of polyhydroxybutyrate with epoxidized natural rubber and maleated polybutadiene. Green Chemistry, 8, 206-213 (2006).

DOI: $10.1039 / \mathrm{B} 508213 \mathrm{G}$

[11] Basnett P., Ching K. Y., Stolz M., Knowles J. C., Boccaccini A. R., Smith C., Locke I. C., Keshavarz T., Roy I.: Novel poly(3-hydroxyoctanoate)/poly(3-hydroxybutyrate) blends for medical applications. Reactive and Functional Polymers, 73, 1340-1348 (2013). DOI: $10.1016 /$ j.reactfunctpolym.2013.03.019

[12] de O. Patrício P. S., Pereira F. V., dos Santos M. C., de Souza P. P., Roa J. P. B., Orefice R. L.: Increasing the elongation at break of polyhydroxybutyrate biopolymer: Effect of cellulose nanowhiskers on mechanical and thermal properties. Journal of Applied Polymer Science, 127, 3613-3621 (2013).

DOI: 10.1002/app.37811

[13] Fei B., Chen C., Wu H., Peng S., Wang X., Dong L., Xin J. H.: Modified poly(3-hydroxybutyrate-co-3hydroxyvalerate) using hydrogen bonding monomers. Polymer, 45, 6275-6284 (2004).

DOI: $10.1016 /$ j.polymer.2004.07.008

[14] Dong W., Ma P., Wang S., Chen M., Cai X., Zhang Y.: Effect of partial crosslinking on morphology and properties of the poly( $\beta$-hydroxybutyrate)/poly(D,L-lactic acid) blends. Polymer Degradation and Stability, 98, 1549-1555 (2013). DOI: $10.1016 /$ j.polymdegradstab.2013.06.033 
[15] de Koning G. J. M., Lemstra P. J.: Crystallization phenomena in bacterial poly[( $R)-3$-hydroxybutyrate]: 2 . Embrittlement and rejuvenation. Polymer, 34, 40894094 (1993). DOI: 10.1016/0032-3861(93)90671-V

[16] Calvão P. S., Chenal J-M., Gauthier C., Demarquette N. R., dos Santos A. M., Cavaille J. Y.: Influence of the rubbery phase on the crystallinity and thermomechanical properties of poly(3-hydroxybutyrate)/elastomer blends. Polymer International, 59, 851-858 (2010). DOI: $10.1002 /$ pi.2799

[17] Chiu H-J.: Miscibility and crystallization kinetics of poly(3-hydroxybutyrate-co-3-hydroxyvalerate)/poly (methyl methacrylate) blends. Journal of Applied Polymer Science, 91, 3595-3603 (2004).

DOI: $10.1002 / a p p .13592$

[18] Parra D. F., Fusaro J., Gaboardi F., Rosa D. S.: Influence of poly (ethylene glycol) on the thermal, mechanical, morphological, physical-chemical and biodegradation properties of poly(3-hydroxybutyrate). Polymer Degradation and Stability, 91, 1954-1959 (2006). DOI: $10.1016 /$ j.polymdegradstab.2006.02.008

[19] Hay J. N., Sharma L.: Crystallisation of poly(3hydroxybutyrate)/polyvinyl acetate blends. Polymer, 41, 5749-5757 (2000). DOI: 10.1016/S0032-3861(99)00807-1

[20] He M. J., Chen X. W., Dong X. X.: Polymer physics (in Chinese). Fu Dan University Press, Shanghai (2005).

[21] Meijer H. E. H., Govaert L. E.: Mechanical performance of polymer systems: The relation between structure and properties. Progress in Polymer Science, 30, 915-938 (2005).

DOI: 10.1016/j.progpolymsci.2005.06.009

[22] L'Abee R. M. A., van Duin M., Spoelstra A. B., Goossens J. G. P.: The rubber particle size to control the properties-processing balance of thermoplastic/ cross-linked elastomer blends. Soft Matter, 6, 17581768 (2010). DOI: $10.1039 / \mathrm{b} 913458 \mathrm{a}$
[23] Wiyatno W., Fuller G. G., Pople J. A., Gast A. P., Chen Z-R., Waymouth R. M., Myers C. L.: Component stress-strain behavior and small-angle neutron scattering investigation of stereoblock elastomeric polypropylene. Macromolecules, 36, 1178-1187 (2003). DOI: $10.1021 / \mathrm{ma} 020477 \mathrm{q}$

[24] Kakroodi A. R., Rodrigue D.: Degradation behavior of maleated polyethylene/ground tire rubber thermoplastic elastomers with and without stabilizers. Polymer Degradation and Stability, 98, 2184-2192 (2013). DOI: $10.1016 /$ j.polymdegradstab.2013.08.017

[25] Wu W., Wan C., Zhang Y.: Morphology and mechanical properties of ethylene-vinyl acetate rubber/polyamide thermoplastic elastomers. Journal of Applied Polymer Science, 130, 338-344 (2013).

DOI: 10.1002/app.39046

[26] Zhou Z., Zhang X., Zhang W., Li J., Lu C.: Microstructure and properties of solvent-resistant fluorinecontained thermoplastic vulcanizates prepared through dynamic vulcanization. Materials and Design, 51, 658-664 (2013). DOI: $10.1016 / \mathrm{j}$. matdes.2013.04.070

[27] Hrdlička Z., Kuta A., Poręba R., Špírková M.: Polycarbonate-based polyurethane elastomers: Temperaturedependence of tensile properties. Chemical Papers, 68, 233-238 (2014).

DOI: $10.2478 / \mathrm{s} 11696-013-0439-0$

[28] Huy T. A., Adhikari R., Michler G. H.: Deformation behavior of styrene-block-butadiene-block-styrene triblock copolymers having different morphologies. Polymer, 44, 1247-1257 (2003). DOI: 10.1016/S0032-3861(02)00548-7

[29] Barham P. J., Keller A., Otun E. L., Holmes P. A.: Crystallization and morphology of a bacterial thermoplastic: Poly-3-hydroxybutyrate. Journal of Materials Science, 19, 2781-2794 (1984).

DOI: $10.1007 / \mathrm{BF} 01026954$ 